\title{
Experiential Learning Approach for Requirements Engineering Education
}

\author{
Gil Regev ${ }^{1}$, Donald C. Gause ${ }^{2}$, Alain Wegmann ${ }^{1}$ \\ ${ }^{I}$ Ecole Polytechnique Fédérale de Lausanne (EPFL), School of Computer and Communication \\ Sciences, CH-1015 Lausanne, Switzerland, \{gil.regev, alain.wegmann\}@epfl.ch \\ ${ }^{2}$ State University of New York at Binghamton and Savile Row, LLC, U.S.A \\ dgause@binghamton.edu
}

\begin{abstract}
The use of Requirements Engineering in industry is hampered by a poor understanding of its practices and their benefits. Teaching Requirements Engineering at the university level is therefore an important endeavor. Shortly before students become engineers and enter the workforce, this education could ideally be provided as an integrated part of developing the requisite business skills for understanding Requirements Engineering. Because much social wisdom is packed into Requirements Engineering methods, it is unrealistic to expect students with little organizational experience to understand and appreciate this body of knowledge: Hence the necessity of an experiential approach.

The course described in this paper uses an active, affective, experiential pedagogy giving students the opportunity to experience a simulated work environment that demonstrates the social/designproblem complexities and richness of a development organization in the throes of creating a new product.

Emotional and technical debriefing is conducted after each meaningful experience so that students and faculty, alike, can better understand the professional relevancies of what they have just experienced. This includes an examination of the many forces encountered in industrial settings but not normally discussed in academic settings. The course uses a lowtech social simulation, rather than software simulation, so that students learn through interaction with real people and are therefore confronted with the complexity of true social relationships.
\end{abstract}

\section{Introduction}

The use of Requirements Engineering (RE) in industry is hampered by a poor understanding of its practices and their benefits. RE education is therefore an important endeavor that can improve the adoption of RE methods in businesses. Ideally this education needs to be provided at the university level, before students become engineers and enter the workforce. Unfortunately, most computer science and software engineering programs do not include RE courses [4].
When they do, these courses are often given in the traditional lecture/exercise format. Only a few publications, e.g. $[2,9,10,19,34]$ report on other types of pedagogy used to teach RE. Teaching RE using games $[3,24]$ seems to be a recent innovative trend. Although games are a powerful source of learning, they must connect with an organizational context to give the needed credibility to RE practice.

Requirements represent the expression of people's desires [12]. To understand and express the desires of people is essentially a social construction. Hence, much social wisdom is packed into RE methods. It is unrealistic to expect students with little organizational experience to understand this body of knowledge and to appreciate even the need for RE methods, much less to be able to use them. It is essential that software engineering students understand the latest, accepted methods and practices in use today in the design of complex computing systems. This, alone, is not enough, however. This knowledge is, of course, required as a professional entry point. If we want to provide more than a shallow understanding of RE to students, we need to provide them with more than just lectures about RE methods and academic problems, where they can exercise the knowledge (or rather the information) they have been provided in our traditional didactic teaching environment. Ideally, it would be good to already have had some, or currently be having, business experience as a prerequisite or co-requisite to an RE course.

As an illustration, the following is an excerpt from a Q\&A with Barry Boehm [8]:

\footnotetext{
"What advice would you give to all the 'youngsters' who are just starting out in software engineering [information systems development] $]^{i}$ research?"
"Spend some time in industry working on real software development [information systems development] projects. You need to get your hands dirty and learn not in your mind but in your heart and gut the problems that real software engineering [and information systems development] faces. This will help you understand what research ideas you have that might be most applicable in practice."

In practice, it requires a curriculum in which students do internships in the middle of their studies. However, even this is no guarantee that they will be 
exposed to the experiences that they will need to fully appreciate and understand an RE course.

The experiences we seek to impart to students are directly linked to the issues found in the workplace when we understand what the business is about and what the desires of people are. A short list of these issues includes: dealing with ambiguity, uncertainty, confusion, fear, time pressure, collaboration, and corporate politics. In sum, what some call the "messy" part of organizations [7]. The messy part, recognized by scientists and mathematicians as wicked problems, exemplify the differences between classroom and workplace problems.

To manage this messy part, it is necessary to bring to bear both techniques and emotions - the heart and gut referred to by Barry Boehm. Whereas the use of specific techniques and algorithms can be learned through lectures and exercises, emotions can only be learned through real life experiences.

We describe the requirements engineering part of an experiential Enterprise Architecture (EA) course delivered at the Ecole Polytechnique Fédérale de Lausanne (EPFL), Switzerland. We explain the reasons we created this course, its essential pedagogical features and the way they were delivered, and the experiences we had giving it. The course was given from 1997 through 2000 as an information systems course with an experiential pedagogy [28]. The case study used in the course and the technical part were overhauled. The course was renamed Enterprise and Service Oriented Architecture (ESOA), and given again in 2007 [30] and 2008. In this paper we relate our experience with the 2007 version of the course with some elements from 2008.

The course was the result of a major effort by a teaching team including a professor, four teaching assistants (TAs) and a visiting professor (in 2007 only). Several members of the team have many years of experience in the IT industry. The course reflects their collective experience. We recreated situations similar to those they themselves faced in their business careers. The course was therefore designed to create a realistic organization in order to provide the students an opportunity to experience the "messiness" they can expect in the workplace. We framed the problems given to the students in an uncertain and confusing reality, often relying only on verbal, word-of-mouth communication as this is an important part of the design and management of information transfer in business settings.

The approach we took with this course included an immersion in a rather realistic social environment, with tools that emulate those used in industry rather than a computer simulation. The students interview real people rather than simulated people and use a custom- made lightweight Material Resource Planning (MRP) system rather than a simulation. The active experimentation is followed by the debriefing of emotional and technical issues as they occur.

At the outset we did not think about a formal evaluation of the effectiveness of the teaching method. We put the bulk of effort into the course preparation and delivery. Hence, this paper is to be read as a narrative that describes our experience preparing and delivering the course.

In Section 2 of this paper, we describe the nature of $\mathrm{RE}$ education related problems. In Section 3, we present the basics of experiential learning. In Section 4, we explain the use of experiential learning in the 2007 version of the ESOA course. In Section 5, we explore our own experience with the course, including examples of lightweight student evaluation. In Section 6 , we outline the related work before summarizing our contributions and delineating the future work we envision.

\section{The Nature of RE Problems}

It has been known for many years that the curriculum in traditional education is partitioned into separate disciplines. Few, if any, courses seek to integrate disciplines. Going through the system, students acquire much factual knowledge about specific areas, but little synthesis is provided.

A slight exaggeration, if any, of the traditional means of teaching college students involves instructors opening the class with Topic A, spending however much time is required through lectures to impart Topic A, assigning homework over this period and following up with an examination of Topic A. The homework and examination problems draw, almost entirely, on the methods introduced in Topic A. The examination is graded and returned to the student. The teacher closes the file on Topic A and moves on to Topic B. This process continues through the remaining topics until the end of the semester. We, as university teachers are unwittingly creating a student mindset that partitions our methodologies. The course is partitioned into a sequential set of several topics with the implication that there is little, if any, relationship between these topics and even less of a relationship between courses. We discovered, while deliberately trying to stretch students' thinking in the similar classes, that students have a difficult time integrating topics and course materials across the topic and course boundaries unless we make extra effort to develop assignments that require this integration in order to successfully complete their assigned projects. 


\begin{tabular}{|c|c|c|}
\hline Experience & Classroom & Workplace \\
\hline $\begin{array}{ll}1 . & \text { Problem } \\
& \text { Definition }\end{array}$ & Well defined. & $\begin{array}{l}\text { Ill-defined. Half of the challenge is just defining } \\
\text { the problem. Often, in fact, a solution is implied by } \\
\text { a mutually acceptable definition. }\end{array}$ \\
\hline $\begin{array}{ll}\text { 2. } & \text { Problem } \\
& \text { Approach }\end{array}$ & $\begin{array}{l}\text { Strongly indicated by most recently } \\
\text { presented classroom material. Problems } \\
\text { tend to be carefully compartmentalized to } \\
\text { reinforce specific methodologies. }\end{array}$ & $\begin{array}{l}\text { Few hints as to how to approach the problem. In } \\
\text { small companies, there will likely be no one to go } \\
\text { to for help. You will, nearly always, be required to } \\
\text { go beyond past studies and methods and may be } \\
\text { required to invent new methods. }\end{array}$ \\
\hline $\begin{array}{ll}\text { 3. } & \text { Problem } \\
& \text { Solutions }\end{array}$ & $\begin{array}{l}\text { Professor always knows the solution. If } \\
\text { the problem is an odd numbered problem, } \\
\text { the solution is in the back of the book. }\end{array}$ & $\begin{array}{l}\text { A solution to the problem will only be apparent } \\
\text { when it has been accepted by management. }\end{array}$ \\
\hline $\begin{array}{l}\text { 4. Problem } \\
\text { Scope }\end{array}$ & $\begin{array}{l}\text { Many problems are "scoped" so that they } \\
\text { can be solved by one person (student) in a } \\
\text { few days or weeks. }\end{array}$ & $\begin{array}{l}\text { The scope of the problem will not be recognized } \\
\text { and you will be expected to produce the resources } \\
\text { and time necessary to achieve the end result. In } \\
\text { general, problems require a team of several people } \\
\text { working over a period of many months. }\end{array}$ \\
\hline $\begin{array}{ll}5 . & \text { Social } \\
& \text { Environment }\end{array}$ & $\begin{array}{l}\text { Working as an individual with implied } \\
\text { competition. }\end{array}$ & $\begin{array}{l}\text { Working as a team member, cooperation being } \\
\text { essential. }\end{array}$ \\
\hline $\begin{array}{l}\text { 6. Information } \\
\text { Levels }\end{array}$ & Accurate, well defined, explicitly stated. & $\begin{array}{l}\text { Vague, unrecognizably ambiguous. Occasional } \\
\text { hidden agendas. Credibility of the source and } \\
\text { timeliness of the information is always an issue. }\end{array}$ \\
\hline $\begin{array}{ll}\text { 7. } & \text { Solution } \\
\text { Methods }\end{array}$ & $\begin{array}{l}\text { Given by an authority figure, usually to } \\
\text { reinforce material recently presented. } \\
\text { Veracity and efficacy never an issue. }\end{array}$ & $\begin{array}{l}\text { May have to invent a new method as part of the } \\
\text { problem solving process. Authority figure often } \\
\text { projects his/her solution as the method of approach. }\end{array}$ \\
\hline 8. Design Team & $\begin{array}{l}\text { Same group of members from beginning to } \\
\text { end of project ( } 14 \text { weeks). }\end{array}$ & $\begin{array}{l}\text { New members join the team and old, experienced } \\
\text { members leave the team, sometimes at the worst } \\
\text { possible times. }\end{array}$ \\
\hline $\begin{array}{ll}\text { 9. } & \text { Stability of } \\
\text { Problem } \\
\text { Statement }\end{array}$ & $\begin{array}{l}\text { Once stated, the problem statement is } \\
\text { rarely, if ever changed. }\end{array}$ & $\begin{array}{l}\text { The problem statement changes frequently as new } \\
\text { information becomes available and new clients are } \\
\text { brought into the picture'. }\end{array}$ \\
\hline $\begin{array}{l}\text { 10. Information } \\
\text { Channels }\end{array}$ & $\begin{array}{l}\text { Heavy use of well-documented, written } \\
\text { form. }\end{array}$ & $\begin{array}{l}\text { Some documentation. But much critical information } \\
\text { is conveyed in "expedient" verbal (sometimes, off- } \\
\text { hand) forms such as one-on-one meetings, } \\
\text { telephone and other informal conversations. }\end{array}$ \\
\hline 11. Conflict & $\begin{array}{l}\text { Conflict with authorities - professors, } \\
\text { experienced university researchers, } \\
\text { teaching assistants - is somewhat } \\
\text { discouraged. Conflict with colleagues is } \\
\text { best ignored as it will go away in } 15 \\
\text { weeks. }\end{array}$ & $\begin{array}{l}\text { Conflict with authorities - senior management and } \\
\text { technical experts is somewhat discouraged. } \\
\text { Conflict with colleagues is best ignored as it will go } \\
\text { away by project end. }\end{array}$ \\
\hline
\end{tabular}

Table 1: The difference between classroom and workplace problems [13]

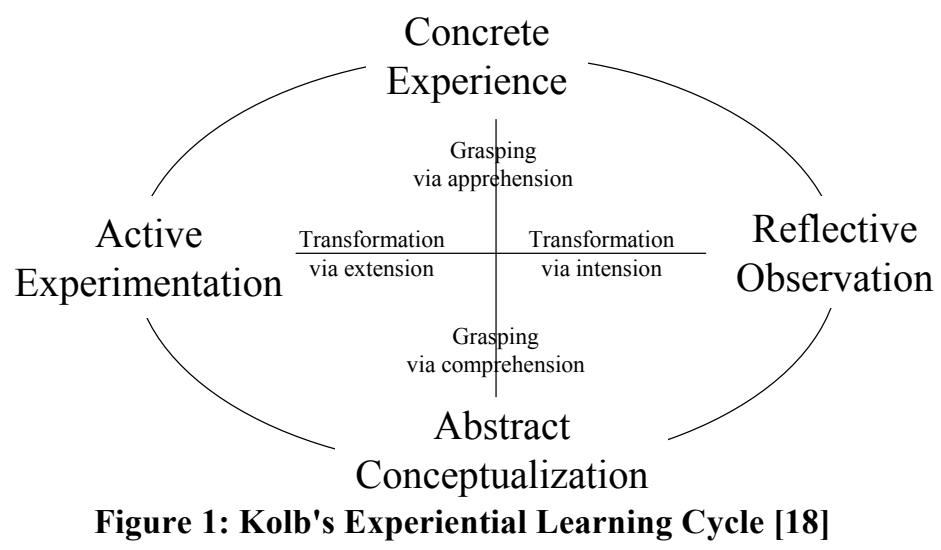

Published in Requirements Engineering vol. 14, num. 4, pp. 269-287, 2009 
Furthermore, the nature of classroom problems is quite different from those experienced in the workplace. Table $1^{1}$ summarizes the differences that we feel are critical between classroom and work problems.

Classroom problems are well defined. They have predefined solutions, known by the professor, they relate to recent material taught in class and their definitions do not change while they are being resolved.

Conversely, wicked problems are often not well defined. The definition, if given at all, changes over time. Their solution is not known at the beginning and whether they were correctly solved will not be known often until long after a solution was proposed. Solving a workplace problem often brings about a host of other problems that could not be foreseen before the solution was implemented - the famous or infamous unintended consequences of each new product entering the marketplace for the first time.

Item 11 of Table 1, i.e. conflict, is remarkable in that the treatment of the problem is almost identical in the workplace and in the student situation. This points to one of our shortcomings in RE education and research alike. We, as engineers, have a tendency to ignore conflict rather than recognize the source of the conflict and use it to learn more about the design problem. Although we recognize several major sources of conflict, such as organizational, attitudinal, diversity of individual experiences and world views, one source we do not readily recognize is ambiguity in the requirements [1]. As further noted in [1], Nygard says the following about conflict [22],

\footnotetext{
“...most people hesitate, in a field with predominantly natural science paradigms, to state clearly that conflicts of interest very often are essential features of system development processes. In fact, most people find it comfortable or advantageous to shut their eyes to this aspect of systems development."
}

We believe that conflict in the early stages is proper and even advantageous when managed properly. Getting to the bottom of such conflicts often pays dividends in surfacing design issues and assumptions that might otherwise have gone unrecognized. In these cases, the conflict moves from human conflict to product conflict as each member of the design team makes design decisions they prefer, for whatever reason, and the final product will exhibit each of the

\footnotetext{
1 Table 1 is the result of anecdotal observations of Gause [10] and the informal discussion of these observations with senior management and technical people drawn from many industries. These observations are consistent with the modified ABET 2000 standards and very recent findings of The Carnegie Foundation for the Advancement of Engineers (See [Sheppard]).
}

implicitly conflicting viewpoints. We believe that the $\mathrm{RE}$ profession and educators need to see conflict as attorneys see it, as a means to getting to the truth of a situation. Attorneys learn to be objective about conflict and, in fact to argue each side of an issue.

Viewing these workplace problems as wicked problems, we can expect the following properties [26]:

- "cannot be easily defined so that all stakeholders agree on the problem to solve;

- have no clear stopping rules;

- have better or worse solutions, not right and wrong ones;

- $\quad$ have no objective measure of success;

- require iteration--every trial counts;

- have no given alternative solutions--they must be discovered;

- require complex judgments about the level of abstraction at which to define the problem;

- often have strong moral, political or professional dimensions which cannot be easily formalized."

Requirements Engineering can be considered a meta-discipline, in that it integrates a number of other disciplines e.g. organizational theory, psychology, sociology, software engineering, ethics. Indeed, RE is a discipline that was created in order to discover people's desires [12] as we have stated earlier. Discovering people's desires is fundamentally a messy, wicked problem.

In our experience, students who have been trained only in the academic curriculum and do not have an industrial background are very often impervious to RE issues. They fail to see the point in spending much time to understand the business requirements. If they are at all sensitive to the question of requirements, they usually believe that it is enough to ask the stakeholders what they want, write it down, and obtain a sign-off. If they have not been exposed to the requirements subject, even the process above is a discovery.

For example, in wicked problems, every trial counts, so it is not possible or advisable to give students the rules of business. They have to live through the problems. However, many students are resistant to this pedagogy and want to receive all the relevant theory and rules so that they can efficiently solve the problem given by the teacher. Also, often students are relatively passive, awaiting the lecturer to deliver the required knowledge to them.

Furthermore, students are unaware of creativity techniques and the need to use them for defining requirements: such techniques as metaphorical and analogical thinking, brainstorming, idea sketching and many other approaches commonly used in other, more mature areas of engineering design. 
RE courses usually teach students how to define requirements that are complete and rigorous. This may give students the impression that stakeholders know what they want or at least are able to clearly express their problems when interviewed or surveyed. In our experience, this is often not the case in organizations. No one stakeholder constituency can possibly know what they want or imagine the full set of opportunities the next system can implement without consulting with many other stakeholder constituencies.

\section{Experiential Learning}

The theory of experiential learning is generally attributed to Kolb [18]. Kolb developed this theory as a way to evolve beyond traditional classroom teaching techniques that favor detached learning of abstract concepts that are disconnected from direct experience. Experiential learning has its roots in the pioneering work of educators such as Dewey, Lewin, Piaget, and Freire. Much of Kolb's arguments in favor of experiential learning sound modern, even though they date to the early 1980s and are built on work that began in the $19^{\text {th }}$ century by Dewey.

Hence, according to Kolb, Dewey's ideas were developed to "meet the challenges of coping with change and lifelong learning." And experiential learning is receiving renewed interest because of, among other reasons, "employers who feel that the graduates they recruit into their organizations are woefully unprepared." [18].

Experiential learning as described by Kolb promotes the idea that experience is at the root of learning and its corollary, intelligence. Experience is seen as an interaction or more as a, transaction between a person and her environment. Abstract thinking is a product of concrete experience rather than knowledge that can be learned from books and lectures.

Kolb integrated the theories of Dewey, Lewin, Piaget, and Freire into four modes of experiential learning. Learning occurs through the confrontation of these four modes. The four modes, usually assembled in what is called the experiential learning cycle (Figure 1) are Concrete Experience (CE), Reflective Observation (RO), Abstract Conceptualization (AC), and Active Experimentation (AE).

In Kolb's own words [18], learners "must be able to involve themselves fully, openly, and without bias in new experiences (CE). They must be able to reflect on and observe their experiences from many perspectives (RO). They must be able to create concepts that integrate their observations into logically sound theories (AC), and they must be able to use these theories to make decisions and solve problems (AE)."
Kolb notes that this cycle is an ideal that is difficult to achieve because learners cannot easily reconcile these modes that require different ways of interacting with one's environment and thinking about it. He further notes that these modes are "dialectically" opposed along two dimensions. The first dimension, called prehension, opposes Concrete Experience of events (apprehension) and Abstract Conceptualization that seeks to make generalizations of these events (comprehension). The second dimension, called transformation, opposes Reflective Observation about experience (intension) and Active Experimentation that seeks to make decisions about future experience (extension). For Kolb, the level of learning is determined by the way the learner can resolve the conflicts present in these two dimensions.

Another aspect that enhances learning was described by Vygotsky as the zone of proximal development. For children, the definition of the zone of proximal development is: "the distance between the actual developmental level as determined by independent problem solving and the level of potential development as determined through problem solving under adult guidance or in collaboration with more capable peers [18]. However, in our case the concept may be extended to what RE students can learn with the help of a teaching team that has RE and industry experience.

As we have seen in the previous section, workplace and wicked problems require an iterative process for their resolution. We hope that during this process the problem itself, which is ill defined to begin with, gradually becomes clearer. We also hope that students comprehend the nature of RE and business problems through their apprehension of the concrete classroom experience.

\section{The ESOA Course}

The ESOA course [28, 30] was designed to follow the experiential learning cycle. In a typical course session of three periods of forty five minutes each, the students were first "plunged" into a simulated real world experience that can be either a business game, an RE style interview session, or a software development task. These experiences lasted for 2 periods (roughly ninety minutes). Most experience sessions were followed by a reflective observation phase, a forty five minute period of emotional and technical debriefing. In the emotional part, the students had the opportunity to express their frustration with the experience they had just gone through. In the technical debriefing, they reflected on the techniques that can be used to solve the problems they faced. Most debriefings were 
followed by a lecture, usually in the first period of the following session. The lecture presented the theory related to the problems and techniques identified during the debriefing sessions. Aspects of contextual interviews were presented after a first session of standard interviews failed to provide a complete picture of the design or process problem to be solved.

The RE phase of the course is the interface between the business understanding and the product or service to be created. The students first need to understand how the business functions and only later can they embark on the RE process, e.g. conducting interviews, drafting requirements. The course was therefore partitioned into 3 modules.

1. Business Game

2. Requirements Engineering and Specifications

3. Prototyping

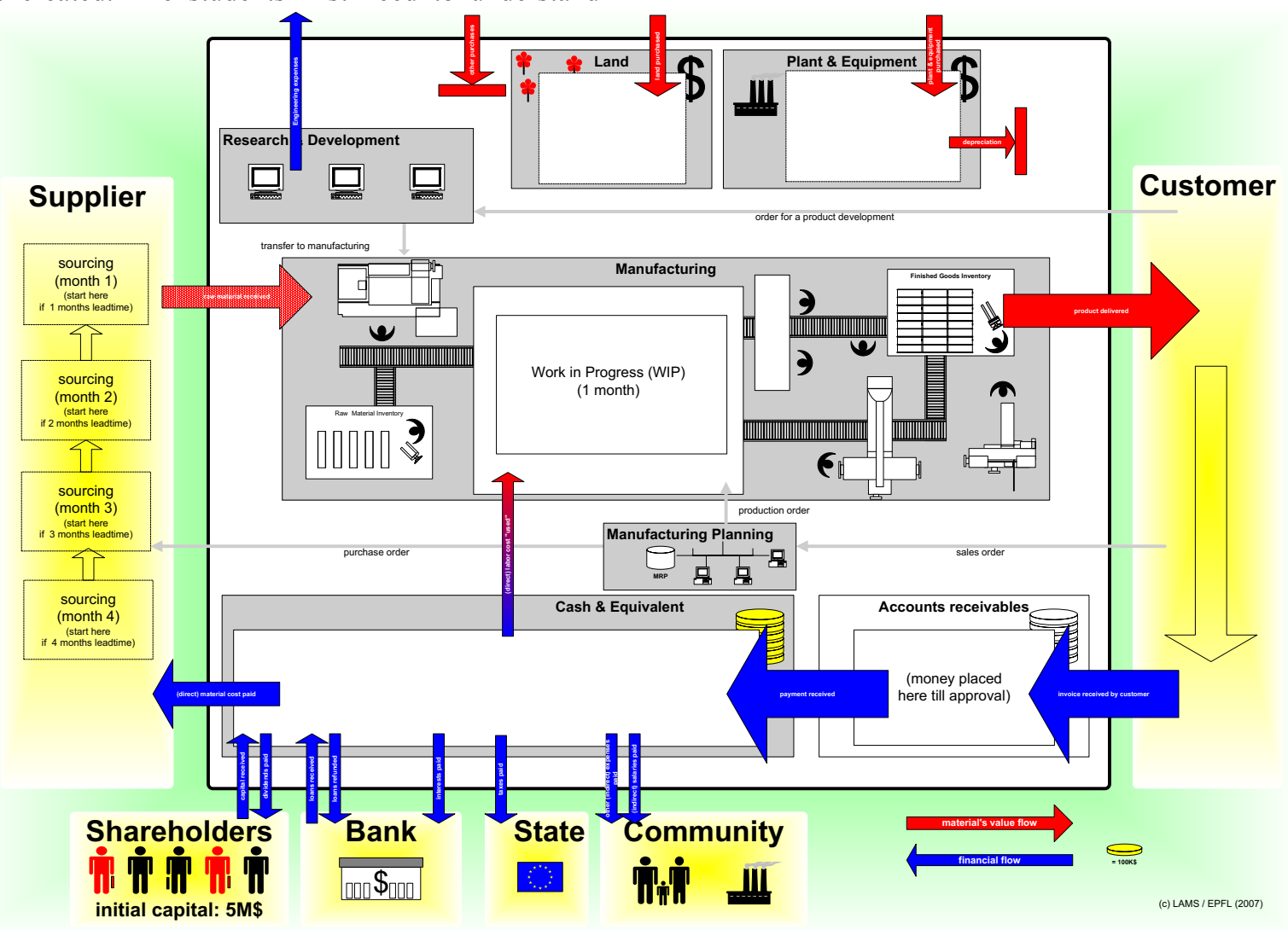

Figure 2: Business game board

In the remainder of this section we describe each of the three modules followed by a discussion of the relationship between the course pedagogy and the nature of workplace problems defined in Table 1 .

\section{Business Game}

The business game was designed for seven teams. In the beginning of this module the students were asked to form these seven teams through a process of self selection. The teams varied in size from about five to eight students.

Each team was considered as a separate company. The companies were to compete within a single market segment to acquire the business of a client company.
The student companies were given identical seed money, a corporate identity and a mission. The mission was to design, manufacture, sell and maintain light airplane diesel engines. We made an explicit choice to base the course on an example from the hard goods industry (airplane engine manufacturing) rather than from the services industry (e-banking, e-government). The reason is that we believe that hard goods offer a more concrete experience because they can more readily be sensed by the students. Once the main processes are well understood, they can then be generalized to the service industry, if needed.

At the beginning of the game each student company was given a Request For Quotation (RFQ) supposedly issued by the client company (an airplane 
manufacturer). The only information given to each team was:

- a game board (Figure 2)

- background information about the RFQ process, a catalog of engine part manufacturers listing existing engine designs and their associated parts

- a simulated 1980s style Material Resource Planning (MRP) application for managing the RFQ process, company financials, financial logging in a journal and order tracking.

The MRP system was custom developed to simulate an independent MRP application for each team of students and an independent MRP for the customer buying the engines. The system was developed in Weblang [6], a web application development language running on top of J2EE. The software is approximately $12 \mathrm{~K}$ lines of Weblang code (approximately $60 \mathrm{~K}$ of native Java code and XML tables). The system also provides a set of web services that are used by the student teams to implement their business processes during the prototyping module.

During the first four weeks of the course, each team had to experience and understand the following issues:

- the RFQ process,

- how to answer the RFQ

- how to decide on buy vs. make

- how to plan manufacturing

- defect and rework management

- $\quad$ quality management

- company finances

The industry related topics are the product design process (e.g. product spec, contract specs, design specs), accounting and finance (e.g. balance sheet and Profit and Loss statement), MRP and quality management (e.g. ISO 9000).

The students were placed under extreme time pressure, instructed to respond to the RFQ in the timeframe of 2 course periods (90 minutes). Every 5 minutes, a bell rang to announce the passing of a fiscal month. Each month, the MRP system would deduct employee salaries and other fixed charges from the company's bank account, creating additional stress. To respond to the RFQ, each team had to select a supplier of parts for their engine, which required a selection of an engine design and a buy vs. make decision. This fixed the cost of an engine and the delay to design a solution and to manufacture an engine. This information was needed to respond to the RFQ.

As a result of the severe time pressure, each student team struggled to understand the background documentation, catalog, game and MRP. We observed that in most cases the game board and background documentation were neglected, so that in most teams there was no overall picture of what was going on. Basic emotions such as frustration and anger surfaced quite rapidly among the students. Several of the complaints indicated doubts about the competence of the teaching team.

\section{Requirements Engineering and Specifications}

The business game module was followed by a seven week module devoted to requirements engineering and specifications. In the first week of the module, the students were given a short statement of a sales problem their company was facing, and instructed to complete a simplified Software Requirements Specifications (SRS) [15] for a system that would solve the problem. They were told that they could obtain more information about the problem by interviewing several internal stakeholders (CEO, CTO and employee), as well as two stakeholders external to the company (a customer and an airplane mechanic). A play script containing the main message to be conveyed during the interview was prepared for each interviewee. Only the main message was detailed so that the interviewees could speak freely without forgetting to say the important aspects of their role. There was only one interview session for each interviewee, so the students had to split up the company teams they had formed in the first four weeks and form functional groups that would interviewed each stakeholder.

After these interviews were conducted, each team wrote its own SRS that they had to present to the company's main investor for approval. In this case, the SRS was not to the liking of the investor who asked to have more information about the feasibility and validity of their proposed solution. To satisfy these demands, the students learned that they needed to better understand the context of the project and therefore do more interviews, most notably by conducting contextual interviews [5] with existing stakeholders and an interview with a customer who needed to be convinced in order to buy their products, Mr. Skeptical. They also had to come to grips with the emotions resulting from the rejection they experienced from their main investor.

We designed the contextual interviews so as to portray the exact situation as it was unfolding, the repair of an airplane that was sent to a repair shop because of engine failure. Each member of the teaching team played a specific role in a separate room.

The airplane owner often called the repair shop every now and then to request information about the status of the repair while taking care of her air club business. The two mechanics in the repair shop tried to repair the airplane in the midst of scattered airplane 
parts, while being harassed by the phone calls of the frustrated airplane owner. The shipping clerk of the BE engine manufacturer tried to send the replacement part needed for repairing the airplane by getting the delivery person to come and pick it up. Planned and unplanned arguments erupted between these actors about issues such as plane repair time, delivery schedules and missing information. The work premises were simulated with LEGO blocks (e.g. airplanes, engines, airplane parts). Each member of the teaching team was dressed as required by the profession he or she was playing. The airplane owner had a flyer cap and goggles, the mechanics wore grungy working clothes. The shipping clerk wore an old shop floor jacket that smelled of mothballs.

In this second round of interviews, the students learned that their understanding of the problem was too partial and that they needed much more analysis to understand the problem and what would qualify as a good solution. They then spent five weeks modeling the enterprise with our SEAM Enterprise Architecture (EA) method [29]. During these five weeks the students designed the overall service to the customer and its partners, the company outsourcing strategy, the necessary changes to the business process and the IT implementation strategy. They used goal-oriented, service-oriented and business process modeling techniques.

\section{Prototyping}

The last three weeks of the course were devoted to prototyping the system described in the SRS and the enterprise models with a Business Process Management (BPM) tool. The students were instructed to develop a prototype of the business process that had been modeled in the previous module using SOA related techniques, e.g. Business Process Modeling Notation (BPMN), Business Process Execution Language (BPEL), and Web Service Definition Language (WSDL). After experimenting with several BPM tools, we selected Intalio [16], an open source BPMN editor and BPEL server, because it was free, easy to install and easy to use. To prototype the business process, the students simply called the web services exposed by our custom-made MRP system in a specific way. Their challenge was to know which web services to call, in which order and how to transfer the parameters from one web service to the next.

In parallel, each team had to rewrite the SRS and submit an executive summary including features such as Return On Investment (ROI) in a language understandable to a non-technical investor. This was done for the students to fully understand the tight relationship between the SRS, the project acceptance and the actual implementation (in our case, the prototype).

\section{Relationship with Workplace Problems}

The course pedagogy addressed the workplace problems in Table 1 in the following way:

- The problems definition given to students was partial and unclear (row 1).

- Very few hints were given on how to approach the problems and the rules of the business game were discovered as the game unfolded (row 2).

- When the work of the student teams was presented for validation it was often rejected by the teaching team playing the role of management (row 3).

- The scope of problems given to the students was totally unclear (row 4).

- The course was designed so that students had to work in teams to play the game and solve the problems (row 5).

- When students interviewed the teaching team as part of the game, the interviewees gave partial and potentially conflicting information (row 6).

- The methods to solve the problems were discovered by the students after the experience, during the debriefing sessions. Theory was given only after these debriefings (row 7).

- Student teams were unstable because students are not required to attend the course. They had difficulties assuming responsibility (row 8).

- The problem statement in the RE module changed from defining requirements to providing business value to customers in order to convince the main investor (row 9).

- Most documentation was given in verbal form through questions and answers during the experience. Very little written documentation was given. No textbook was used (row 10).

The following testimonial by one of the 2007 students, who is finishing her Master's degree, after about 4 months in the industry, makes a nice link with Table 1:

\footnotetext{
In the course, it was also not always clear what was expected from us, which is unusual in an environment where our minds are shaped to solve a given problem. This was very uncomfortable and was perceived as a lack of organization. Now that I'm in a company, I realize how ill-defined and unclear are the problems and the goals and now understand why we had to go through this during the course. The situation is still uncomfortable in the real world, but at least I'm confident that tools exist to help me clarify things and plan to use them in the next steps of my project.
} 


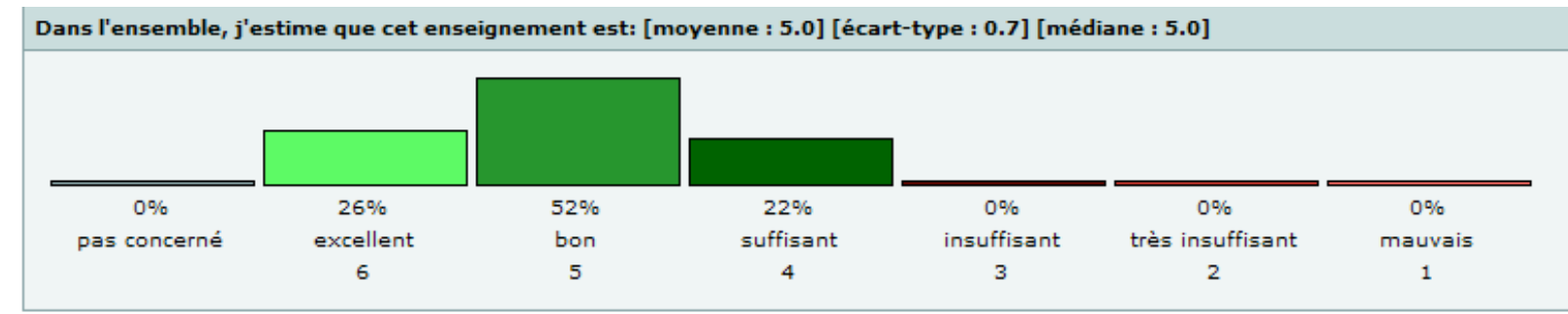

Translation from French:

Text at the top: Globally, I consider that this course is: [average: 5.0] [standard deviation: 0.7] [median: 5.0] Bars from left to right: not concerned, excellent, good, sufficient, insufficient, very insufficient, bad.

Figure 3: 2007 Course Evaluation

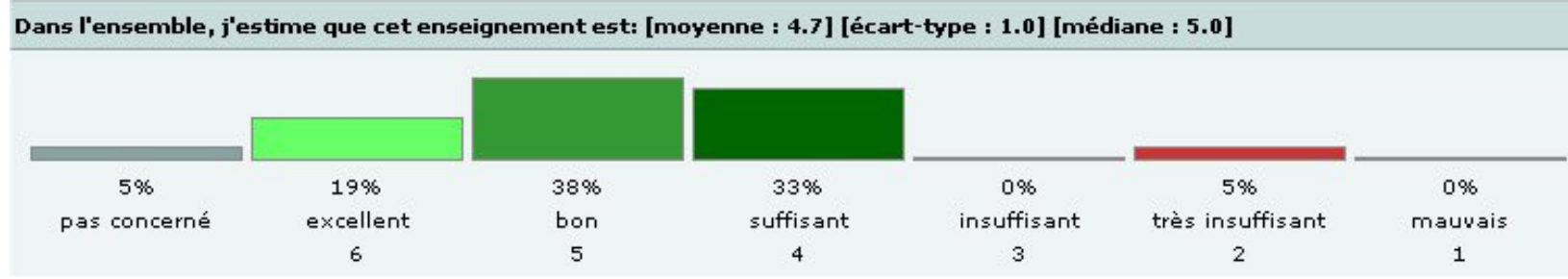

Translation: same as in Figure 3.

Figure 4: 2008 Course Evaluation

\section{Experience with the Course}

In this section we describe some of our thoughts about the way we delivered the course and what we learned from it.

\section{Resources}

The course was developed over a period of about two years by the professor in charge of the course and two TAs, all working part time on this project. All three have substantial industry experience. Several students' semester and master's projects were used to create the business case and to explore technical possibilities related with the MRP system and the BPM tool. The MRP prototypes developed during these projects were eventually scrapped. The MRP was redeveloped solely by the professor in charge of the course: in a challenging task that took two months. This development required a solid business and software engineering experience (J2EE development).

A new version of the MRP was developed in 2008. Our goal was to develop a better architecture of the code, to increase reliability and reduce errors, as well as to create a $\log$ of the financial transactions that can be used to map the game events and the business processes.

In 2007, during the semester, the professor and one senior TA had six hours contact time and one to two days per week to prepare the subsequent week's course activity, as well as to debrief the current week course activity. The other TAs had almost the same load, in terms of contact hours and debriefing, but much less preparation time. The scripts we prepared for each role in the play and the fact that the roles reproduced simple real-life behaviors, helped reduce the preparation time for the TAs. In 2008 we had a new TA who did not know the subject and who was trained to do the contextual interview of one of the lesser roles in a couple of hours. The roles that required in-depth knowledge of what we wanted to show the students were played by the professor and the more experienced TAs.

In 2008 the TAs' preparation time was quite reduced, most of the course material had not changed. The most time consuming task for the TAs was adapting to a new version of Intalio. We can estimate that over the whole semester the TAs spent one day a week on the course including contact hours, debriefing and preparation. The professor's load had increased to compensate for the TAs' decrease. In both courses, the oral exam took three full days (professor, one TA and one expert).

The course was allocated one large classroom with movable tables and chairs. This was important to accommodate non-standard seating arrangements. Students needed to be able to communicate with their team mates much of the time rather than facing the professor in the traditional classroom or lecture mode. 
In 2007 the interviews were held in different corners of the room. We also used individual offices for the contextual interviews. Indeed, these were held in parallel so that the students would be able to live through the real-time interactions among the stakeholders, This scheme was applied partially in 2007 and perfected it in 2008: where the interactions by phone and simulated mail between the stakeholders played by the professor and TAs worked really well.

As class size was nearly the same in both years, it is difficult to infer how the role playing activities may scale to larger class sizes. We can confirm that the business game is designed for only 7 teams and that teams that extend beyond 5 to 7 students tend to have only a few active students while the others just wait for the results. The same is true for the interviews, contextual or not, where two or three students actively participate and the others only listen. We had five concurrent standard interviews played by one professor or TA each and 4 concurrent contextual interviews, three of which were played by one professor or TA and one contextual interview played by two TAs. We therefore had between 7 and 10 students per interview. It would have been better to have 3 to 5 students conducting each interview but this was not feasible with the resources we had available.

To scale to bigger classes, the business case has to be adapted to accommodate more interviews (with more TAs) or several interview sessions have to be scheduled. Because students don't always ask the same questions in the same way, and professors and TAs don't always give exactly the same answers, having several interview sessions runs the risk of creating confusion. We avoided this risk by running the interviews in parallel. We could, however, build the course precisely around this confusion. It could simulate what often happens in real life, where different people receive different answers at different times concerning the seemingly same problem.

\section{Course Evaluation}

Again, the 2007 and 2008 courses were attended by very nearly the same number of students, approximately 40 out of a total of about 100 eligible students. This is considered to be very large attendance for an elective course. It should be noted that the students voluntarily selected the course with no coaxing or other instructor influence. The 2007 course was well evaluated (see Figure 3) with $78 \%$ of the students rating the course as excellent or good. This percentage dropped in 2008 with only $57 \%$ rating it excellent or good (see Figure 4).

The difference in student appreciation can be explained in three ways: (1) the number of TAs dropped from 3 full-time to 1 full-time (spread over several people). In addition, their involvement was of a different nature (in 2007 it was a group project to develop and give the course, in 2008 it was essentially an obligation). (2) The contents of the course evolved and this destabilized the TAs. The 2008 course emphasized the mapping of theory to practice. Much work was done in the business part, on mapping the contents of the MRP financials $\log$ to the business processes and to the quality system. This was new and not known by the TAs. (3) More theory was added and this removed some of the experiential related fun of the 2007 version.

We believe that this drop in the rating is mainly due to a decrease in the level of involvement of the teaching assistants who were busy finishing their PhD theses. This is a reminder that a teaching team's heavy involvement is crucial to the success of an experiential course.

In the fall of 2008, we sent a survey to fifteen of the 40 students from the 2007 class. The short questionnaire (see Appendix) was sent to students who maintained contact with our research lab and those of whom we could find the e-mail address through the course blog and social websites such as LinkedIn. We received seven responses.

We wanted to probe the students for their feelings about the effects of the course on their workplace experience. We only contacted the 2007 class students as most of them graduated in late 2007 and would have a few months of industry experience.

The responses were mostly positive with 4 out of the seven respondents rating the course as useful to very useful for their career. The respondents noted the practice of and role playing as aspects they liked about the course. The improvements they were almost unanimous in recommending better structure and better explanations of the tasks they were requested to perform. Curiously, this is precisely what we didn't want to provide them. However, the course slides and flow between chapters (as noted by two respondents) can definitely be improved.

As a general note, the authors put the bulk of effort into preparing the course materials and plans and readying the faculty and teaching assistants for the offering. Formal evaluation came as an afterthought once the course proved to be a success, hence the qualitative anecdotal evaluation presented here. Our advice, in the way of formal student evaluations for experiential courses, is to measure the following: 1) course effectiveness in developing leadership, team, problem solving, communication skills (including writing, speaking, and listening, in an industrial setting 2) the relative difference in student effectiveness in eliciting and developing business requirements 
between students studying the subject material didactically (control group) vs. students participating in the affective class, and 3 ) the aspect and formative skills based on a) student self-evaluation and b) independent visiting senior technical and management assessment based on final student team reports and presentations.

\section{Acceptance of the Experiential Learning Style}

The course is immersive and problem-based. It was very important to explain frequently why the course was so different from the other courses (at least in the first and second weeks and at the beginning of each section). The two comments below illustrate that for some (most) students the course structure was understood.

\footnotetext{
"The course is very well structured, many new concepts are presented, but easy to understand and learn due to the fact that we are directly placed in a situation before we learn the theory. We discover the different problems encountered by ourselves and then the theory enables to consolidate the knowledge learned during the experimentation."

"The class material is very interesting, but often we don't have enough theory to do the exercises and we spend too much time not knowing what to do and asking questions. It would have been much better to have theory part with all information, then clear task description and finally 10 minutes (measured in a Swiss way) to do what we have to do. Apart from this the class is very interesting and the material presented is useful."
}

However, up to the last day, a few students did not accept this style of learning, saying that the course was disorganized and that they preferred lectures followed by clearly described exercises. It is surprising that they remained in the course despite this.

A few students complained about the class-level debriefing being boring because most groups had similar findings. This problem could be alleviated by not asking the student teams to present their learning individually, but to have the professor make a synthesis of each of their comments. This would, however, reduce the active participation of the shy students.

At the beginning of the course, we made sure the students understood that their performance during the course would not affect their grade. The grade was only the result of their performance during the final oral exam. Our intent was to enable them to live fully through the experiences of the course without being afraid of being judged so as to maximize learning and risk taking. In hindsight, this also enabled the teaching team to interact more freely with the students without the fear of judgment on either side. Of course, this made the job of grading much more difficult at the end of the course.

\section{Knowledge Transfer}

The final exam was oral in which the students had to solve a new problem, answer a theoretical question and explain a detail (chosen by the professor) on one of the models produced by their team during the course. This was a measure we chose in order to offset the lack of continual assessment and to identify those students who did not participate in their team work,

The average and the distribution of the grades of the 2007 and 2008 were identical (4.9). We had approx. 40 students. Typically 25 students were above 5.0 and 3 to 5 students below 4.0. These are considered to be very good results. We also made a correlation between the student grade and the student participation in the class, as observed by the professor. As the work was done in groups, quite often the work was executed by one or two students - with the others watching. Our statistics show that the students who took the course passively received, on average, one point less. It was also surprising to see that some of the very advanced students (who run a business in parallel) got very low grades - even with a regular participation in the course. Our hypothesis is that they assumed that they were good developers and they did not have the openness to question themselves.

It was also important to explain in the course, on multiple occasions, how the exam would be structured. This was essential to allow students to know what to learn and to help them feel more confident.

From an anecdotal viewpoint we mention that students contact us frequently mentioning that their understanding of the course's vocabulary helped them to obtain internship positions in the industry. Some students were hired by consulting firms and contacted us because they were interested in presenting their work in the course. Some of the students who took the course later made their master's project in industry under our supervision. We noticed that they do not always notice that the knowledge gained in the course can be used in their master's project. Our main coaching activity is to work with them on realizing this and to promote the reuse of the knowledge. This is an area that needs to be further improved.

\section{Credibility}

One of the extremely important aspects of the course is its credibility. As the course puts the student in a stressful situation, the student might infer that the course is disorganized. With adequate communication, the students eventually believed that the course puts them in a situation related to a "real-life" situation and that they can learn from this experience. 
During the first sessions of the course, we were repeatedly challenged by the more skeptical students in regards to our handling of the course and its business expertise. The challenge was expressed by comments during the experimentation and as open criticism during some of the emotional debriefing sessions.

Our participating visiting professor presented a lecture dealing with the differences between industry and academia, citing professional society surveys, leading engineering educators and executives consistent with, and summarized by Table 1 . He was also careful to give the industrial backgrounds of the instructors in the meetings with student teams, whenever appropriate.

We did the following to raise the course credibility:

- We were not shy in describing our accumulated industrial experience

- We invited four industry practitioners who presented real projects they were involved in (one in each module of the course and one for the overall course). Even without prior briefing of the speakers, their presentations were close enough to the material taught in the course for the students to believe in what they experienced.

- The professor and the four TAs were deeply involved in the entire course (especially in 2007). The students reacted very positively to this full involvement.

However, we were not really prepared for the students' doubts in our abilities and our handling of conflict is one of the areas that need improvement.

\section{Emotional Relations}

The debriefing sessions addressed both emotions and technical knowledge. For example, in the first sessions, the students learned to manage stress by becoming specialized in different roles, thereby learning to work more effectively as a team. In the debriefing sessions we discussed the difficulties they had in assuming these specialized roles. Some of these difficulties stemmed from the fact that some students did not attend all the sessions of the courses (because they are free to attend or not). Hence, if a student assumes the role of CFO of the company and this student misses a class, the company has no more access to its financial situation. This also points to the tension between specialization and generalization [32]. In the related theory sessions, we explained some of these tensions. It is an aspect we will address more in future versions of the course.

The course does not address interpersonal relationships. For example, during the interviews, students behaved differently depending on who they interviewed. The teaching assistant playing the CTO, for example, had the impression that the students were quite aggressive with him. An attitude he attributed to them seeing him as one of theirs. The assistant playing the CEO, on the other hand, had the impression that the students who interviewed him were very polite, almost intimidated. This is an aspect we could add in the future.

For the first round of interviews the students had to assemble groups that would interview each stakeholder separately. This forced them to leave the relative comfort of their established team and form a group with students from other teams. This is very similar to cross functional teams that need to assemble in an organization, an often painful process. It seemed that the students experienced similar pains as those observed in industry. At first they were unable to form the new groups and apathy set-in. It took the courageous and firm action of one of the students who came to the front and literally gave orders to the class for the groups to form.

The course ended with an outdoor farewell party in which most of the guest speakers were present and the students could talk about their careers. This party was necessary to end the course in a socially satisfactory manner. The teaching team felt that the stress and the emotions shared during the course needed to be relieved through a social event. This was very enjoyable.

\section{Academic Knowledge vs. Practical Experience}

Our goals for the course were to provide an integrated view of business and IT aspects, as well as to provide a context in which students could place the functional knowledge they learned during their studies. However, the course presented additional material which was not covered in the rest of the curriculum. For example, the structure of the main business processes (product sourcing, development, manufacturing), and enterprise modeling techniques are not taught elsewhere in our CS and SWE curriculum. During the exam we found that these concepts could be grasped in more depth. More specifically, the course goal was to give the students a feel for real work in organizations and some concrete knowledge on key business, RE and implementation concepts. The second aspect was not as successful as expected in 2007. In 2008, we attempted to address this issue by asking students to read some of our research papers on these concepts and by offering quizzes more systematically.

The papers were used to present the course structure [30], the models developed [29], the theoretical foundations such as the modeling ontology we used 
[31], and goal modeling [23]. These papers were given for reference. We did not prepare quizzes about them. The papers helped the students to realize that the approach taught was the result of extensive research. It was instrumental in increasing the course credibility an essential point. In addition, it was an opportunity for our PhD students to present their work. Quizzes need to be added to insure that students read the papers and make a synthesis of what they read.

Quizzes were made on the business part of the course. For example, we asked students to modify financial reports according to events that happened to their company (e.g. extraordinary sale, inventory obsolescence). This was essential for the students' understanding. It is only by responding to the quiz that the students became confident that the knowledge they acquired experience was reusable.

We noticed that there is a possibility that requiring more theoretical work might dilute the concrete, active and fast-paced properties of the course. We need to find the right balance between these two opposing requirements.

\section{Effect on the Teaching Team}

As can be expected from an active, experiential course, it had a substantial and lasting effect on our research and our way of working. The course was developed collaboratively among the professor and teaching assistants. Most of the lectures were given by the professor. However, each TA had to give one lecture related to their research topic. This presentation was co-developed with the professor. In addition, after each course, we had a team debriefing to discuss the course contents. In these debriefings - which sometimes were quite long and often very emotional we uncovered issues on which we did not agree. We also reinforced our understanding on what we agreed upon. This helped us to publish significantly more of our research, compared to previous years, while giving the course. When we gave the course, it also coincided with our decision to give up on independent offices and to work all together in a common open office, which further improved our collaboration and research.

The students, too, became far more active than in traditional courses. They thought that because during the whole course we kept challenging them on their way of working together, they could do the same to us. They therefore actively challenged our way of working as a teaching team and demanded that we do the same. For example, in the last session of the course, we asked each student team to present what they learned during the course. When they were done, they asked us to do the same. These were wise remarks and we improved our working style significantly with the help of the students.

\section{The Fit between the Course Structure, Enterprise Modeling and RE}

When we first designed the course in 1997, we used different modeling methods for each of the three modules. During the interruption of the course, from 2000 to 2007, we were busy developing the SEAM enterprise modeling (or enterprise architecture) method [29] in order to seamlessly model an organization from its position in a market segment down to its IT systems. The resulting hierarchical structure of SEAM perfectly fits the course structure. Both structures enabled us to explain to the students the necessity of using RE methods as a bridge between stakeholders desires (at the marketing level) and their implementation at the IT level. It is our hope that this contextualization will help students to understand what $\mathrm{RE}$ is all about and to integrate at least part of the wisdom that RE methods incorporate. On the flip side, all the methods we teach (e.g. marketing positioning, value modeling, goal modeling, business process modeling) are contextualized within SEAM, with the exception of Contextual Inquiry [5] and the IEEE 830 standard [15].

Of course we recognize that the existing state of the art in RE is important. Methods such as i*, KAOS, Volere, use cases, e3value and notations such as UML are presented in the state-of-the-art section of each module. In addition, our guest speakers usually present commercial methods used in their company and that have the same purpose as those taught.

\section{The importance and challenges of human simulation}

We purposefully chose to avoid using software simulation tools in the course, despite the reduction in resources that they afford, as identified in [9]. We believe that a software simulation such as the one presented in [9] can only account for a finite number of situations and that students will no doubt detect this closed nature and will quickly learn how to get around it. Simulation by human beings, i.e. faculty and teaching assistants, is open ended. The entire gamut of human emotions, as well as a very diverse set of situations, can be portrayed. This can result in unintended consequences that offer unique learning opportunities for both the teaching team and the students. An anecdote from the 2008 version of the course is a good example about the kind of twists that can happen with human simulation. Remember that we were holding the interviews (standard and contextual) in parallel (originally as a simple way of saving time). 
During the contextual interviews when we were showing the problem of the repair of an airplane engine, we had failed to completely coordinate the stories between the customer of the engine manufacturer and the mechanic in charge of the repair. It so happened that the customer and the mechanic gave contradicting figures about the time the airplane had been in repair. The customer claimed that the airplane had been in repair for three days whereas the mechanic only admitted to having the airplane in repair for one day. The students were also witness to an argument about this between customer and mechanic. The students' obvious interpretation was that the mechanic was caught lying. To our recollection, none of the students had challenged the customer's figures. This unintended incident triggered us to conduct a discussion about interpretations of social situations. In this discussion, we asked the students to suggest as many reasons as possible that could explain the difference in the figures given by the two stakeholders. Unfortunately we did not keep records of this discussion. We conducted a similar discussion at the REET 2008 workshop asking the participants to think of all the reasons for a customer and a mechanic to disagree about the number of days an airplane had been in repair. The answers the workshop participants suggested in just a few minutes are the following:

- The definition of repair shop might have differed from the customer perspective and the mechanic perspective

- Maybe the mechanic saw the airplane only one day because it was stored somewhere else or the mechanic was away from the shop

- Maybe there is a buffer between repair times

- Maybe the mechanic was lying

- The tracking report of the repair was not up to date

- The customer and mechanic did not share the same concept of day, e.g. work day vs. weekend day.

- The customer and mechanic were in different time zones

- Maybe the airplane was repaired in one day but was not ready to be released to customer until the repair bill had been paid.

Notice how "the mechanic is lying" is only one of the hypotheses and not even the first one that was expressed. The students, however, were quick to conclude that this was the only possibility that explained the difference in the figures reported by customer and mechanic. The discussion about the other possibilities may have helped them to acquire a broader view of problems in organizations and the danger of jumping to conclusions.

There are some challenges linked with the use of human simulation. Because the roles are played by the same people who give the course, it is important that students know when they are talking to a person playing a role in the game and when they are talking to the same person acting as the teacher. It often required a concerted effort to maintain this separation. In the course we tried our best to maintain it through our dress code. If we were dressed for our role in the game our behavior was that of the role. As soon as the role playing phase was over, we removed our costume to signal the students that we now would answer their questions as the teaching team.

A second challenge is to maintain the balance between planning and improvisation. If everything that an actor says is planned in advance, there will be no unintended situations such as the one described above and learning will be limited. If there is not enough planning, some crucial information that the game is built upon will not be given to students and the whole simulation will break down. Maintaining this balance is delicate and demanding.

Some of the simulations of this course required the assignment of specific roles. Students were instructed to assign their teammates to such roles as development of research, team $\mathrm{CEO}$, marketing manager and software developer. The teaching team assumed such roles as the prospective product client (Mr. Skeptical), engine mechanic, aircraft owner, shipping clerk. In the teaching team situation, these roles were assigned to provide reality to the situation. It is highly desirable that faculty and selected teaching assistants have working experience. The teaching team behaved as normally as possible in their assigned role. Nature plays enough tricks on us without our further confounding these situations. We assigned roles in accordance with each member's experiences, providing, as much as possible, all too familiar situations.

\section{Addressing Scope Creep in Experiential Settings}

The following interview is discussed in detail for the purposes of illustrating the well-known problem of scope creep. Scope creep was not part of the learning objectives for this course and the interview just happened to expose this aspect due to the emerging interaction between the visiting professor playing $\mathrm{Mr}$. Skeptical and a very eager student playing the company's marketing manager.

The case involves an afternoon meeting between the $\mathrm{BE}$ marketing manager and the owner of a small 
airplane rental business in the Swiss Alps with a rental fleet of just over one-hundred aircraft. The marketing manager was assigned to this position by his fellow design team members. The assignment was made as a collective decision by the team members based on their perceived relative strengths, experiences, and skills and the team member's interest in serving in this role.

The purpose of this meeting is to test the design team's current understanding of the design problem based on the knowledge and interests of a more-or-less typical customer. The BE marketing manager knows that this customer is only one client with one set of business requirements but the customer is nonetheless an important customer seen as representing a potential market for over one-hundred sales units. The client is also seen as an influential individual who might provide an endorsement for future sales.

Instructions to the design team:

It was explained to the team that, in practice, the full design team would NOT normally be present in this type of meeting. The design team was told that the purpose of having them present, in the simulation, was for them to experience some of the common benefits and pitfalls of requirements elicitation procedures. They were instructed NOT to enter into the conversation or otherwise communicate in any way, including gestures, with their appointed marketing manager. They were instructed to take notes in preparation of discussing their findings after the meeting's conclusion (and outside of the case simulation environment).

Interview of $4 / 26 / 07$ at the end of Phase II, the requirements elicitation phase:

The following is the detailed dialogue between the student acting as the BE marketing manager and a visiting professor/consultant in the role of $\mathrm{Mr}$. Skeptical, owner of the air club with a little over 100 private airplanes for rent. The visiting professor has had many years experience in consulting with clients in situations similar to this case and followed the instructions of being natural in bringing up issues that were of genuine concern. As the name implies, Mr. Skeptical is a careful thinking individual who must be convinced that his business will greatly benefit from the purchase of aircraft diesel engines with their advanced information and control functionality. The full team of seven students, including the marketing manager, was present in the meeting. The primary purpose of this meeting is to check the team's understanding of the requirements as seen through a key user's (Mr. Skeptical) eyes. It should be noted that
Mr. Skeptical and the student marketing manager were, once again, reminded to interact naturally and honestly within their assigned roles. Neither was to try to manipulate the situation or the other person or to be unnatural in any other way.

The dialogue begins in the earnest part of the meeting after introductions and pleasantries have been exchanged.

[Mr. Skeptical]

You know, I have always followed the old adage, "Never buy a car in the first year of a new model." I learned this as a young automotive designer but let my emotions get the better of me just once. I bought a new car in the first model year of the manufacturer's front wheel drive model. The manufacturer had an excellent reputation of many years for the production of rear wheel drive automobiles. Within the first 12 months I had to have the car towed twice, once for a wheel bearing failure and once for an engine failure requiring an engine overhaul. I had to rent a car two other times, once because the dashboard engine warning message flashed "SERVICE NOW" and in the other incident, the transmission had to be rebuilt. This is bad enough as an inconvenience (all repairs were under warranty). Do you have any idea what kind of trouble I would be in if one of my planes has a Diesel engine failure with a tourist over Zermatt?!

[marketing manager]

We know, through analysis and exhaustive testing that Diesel engines are much more reliable than gasoline engines. There is a long history of the Diesel engine in trucks and automobiles to support this.

[Mr. Skeptical]

But taking a Diesel engine to 5,000 meters in the mountains is much different than being on the ground where you can pull off the side of the road if the engine isn't performing.

Our records indicate our current fleet reliability to be 1.86 failures per thousand hours. What have you experienced with your engine?

[marketing manager]

We are seeing 1.66 failures per thousand hours.

[Mr. Skeptical]

For the moment, let's just imagine that your turbo powered Diesel has an acceptable power to weight ratio, can give me the necessary torque under the usual - and even extreme - flight conditions, I understand that this engine comes with the latest of instrumentations and communications technologies. 
[marketing manager]

That's right.

[Mr. Skeptical]

Can you give me an on board proactive engine diagnostic functionality that, for instance, provides reminders for various engine servicings?

[marketing manager]

We not only can do this but we are now doing it.

\section{[Mr. Skeptical]}

Taking advantage of the latest sensor and micro sensor technologies and data analysis, visualization and forecasting methodologies can you provide the pilot, in flight, and the mechanic, on the ground, early warning indicators for preventative maintenance (on the ground) or engine failure avoidance (in the air)?

[marketing manager]

We can do that.

[Mr. Skeptical]

Can you provide the pilot with the nearest landing place to obtain the service required should the warning indicator be sufficiently dire?

[marketing manager]

We can do that.

\section{[Mr. Skeptical]}

Can you also provide the pilot with the least expensive or quickest repair locations considering the presence of the appropriately certified mechanics and parts availability and can you also provide the expected time and cost estimates for each of the acceptable alternate landing spots?

[Marketing manager]

We can do that.

[Mr. Skeptical]

I'm very impressed with the information side of things. In fact, with these advanced diagnostic tools, it appears that the early warning functionality makes some of my reliability concerns moot.

[Marketing manager] EXACTLY!

\section{[Mr. Skeptical]}

Let's get back to the physical aspects of the Diesel aircraft engine. Can you give me vibration and noise, fuel consumption, and torque comparisons with our current fleet? [marketing manager]

I can and will do that.

[Mr. Skeptical]

And, oh yes, can you give me a ball-park cost figure if we decide to purchase these engines?

[marketing manager]

Our price would be somewhere in the 60,000 SF range.

At this point the meeting came to a conclusion due to Mr. Skeptical being called out of the room for an important personal matter. The usual amenities and pleasantries were exchanged between the marketing manager and Mr. Skeptical and the marketing manager promised to get back to Mr. Skeptical within the next week on the vibration, noise, fuel consumption, and torque comparisons with Mr. Skeptical's current engines.

As we pointed out before, the issue of scope creep was not a learning objective. Hence we simply failed to follow-up on this interview and investigate the issue with the students so that they could really learn from this experience. To some extent we wanted to avoid scope creep in the course itself and therefore avoided acting on an aspect that was out of the course requirements. Our failure to seize this opportunity to teach an important aspect of RE, may show that scope creep is not necessarily always bad.

If we had acted on this opportunity, we would have raised the following points (The students and visiting professor/consultant assume their student/teacher identities for purposes of discussion):

- Design team excluding the marketing manager and Mr. Skeptical

- How did you feel during the interview process?

- What, if anything surprised you about the interview?

- Do you think Mr. Skeptical and your marketing manager were completely candid with each other?

- Do you think each were acting in the best interest of their companies, in the best interest of obtaining accurate information to advance the design process, or in their own self interest?

- How well did your marketing manager represent your interests in and the primary purpose of the meeting - to test for understanding 
and completeness of the current requirements?

- Marketing manager's comments in response to the design team's comments

- General discussion of remaining issues -

A major result of this particular session was the vivid illustration of scope creep and its related cousin, wishful client expectations. What is not clear from the transcript is whether Mr. Skeptical was, in reality, becoming more enthusiastic with each of the market manager's positive responses to the ultimate functionality expressed in the least expensive or quickest repair locations question or he was actually applying the orange juice test $[12,33]$, in which the client defines what he knows to be an impossible task (requiring the kitchen staff to serve fresh squeezed orange juice to 1000 breakfast banquet attendees at 7 o'clock in the morning). In the first case, the marketing manager gave Mr. Skeptical unrealistic expectations about functionalities that could most likely not be met. In the second case, Mr. Skeptical will not trust the marketing manager's answers and judgments.

\section{Related Work}

There are examples of courses developed by engineering schools that make heavy use of affective pedagogy. One such graduate course, Heuristic Problem Solving [27], was developed in 1970, and has been actively offered since its inception. A current course derived from Heuristic Problem Solving pedagogy with a special emphasis on the design and analysis of manufacturing systems is now in operation as a two-semester, senior, Capstone design class for industrial and systems engineering students [2]. More recently, there has been a growing interest in project based teaching [14] and more specifically Problem Based Learning approaches to Software Engineering $[11,20]$. Logically, these courses focus on the technical Software Engineering skills, project management and teamwork with less emphasis on requirements. However, their pedagogy is very close to the one we propose and they integrate assessment as part of the course delivery.

The participants in a 2004 panel on RE education at the $12^{\text {th }}$ RE conference discussed the need to give students RE experience as well as the wicked problem issues. They also mentioned several courses that used experiential techniques. We found only one publication, however, about a course of this kind [34]: it reports on the use of role playing in an RE course. The goal of the course is to teach 1) Interviewing and groupware skills for requirements elicitation and validation. 2) analysis and modeling skills for problem solving. 3) effective writing skills for specifying requirements. Our course addresses all three skills but contrary to [34] is not designed to teach students how to write unambiguous, consistent, and complete requirements. Rather we focus on writing correct requirements in a way that stakeholders will understand, i.e. that match their technical and business understanding level.

Some publications about courses with active pedagogy were published at the REET 2005 workshop, e.g. [10] and [19]. [9] describes an immersive RE course that uses an IT simulated environment. They mention that the course was given in the past with a TA based simulation but that this was too costly, hence the move to IT based simulation. Business games and computer based simulation are also widely used in business education, e.g. for supply chain management [21].

More recently, courses based on games, e.g. [3, 24], have been introduced to improve RE education. Incorporating such games in our course could be an important improvement.

It is worth noting that our course used human simulation and much debriefing effort to avoid the closed nature of computer based simulations.

\section{Conclusions and Future Work}

In this paper, we have described an active experiential RE course and its underlying theory. The course was designed with two major objectives in mind: (1) to ease the transition of students into the workplace (2) to give students an understanding of Enterprise Architecture issues, i.e. business and IT alignment, RE, BPM and SOA development.

The current version of the course provides a platform to which we can add advanced experiential learning issues such as accommodation, apprehension and comprehension. We could do more to consciously integrate the zone of proximal development concept and in particular to expand each student's zone of proximal development to encourage metaphorical and analogical thinking and other creative mechanisms including John-Steiner's cognitive pluralism [17].

We could add specific sessions on conflict management, as well as ethics [4]. An on-going assessment as suggested in problem-based learning methods will be a definite improvement. A formal evaluation by external experts in pedagogy could be a good leverage for the improvement of the course. A link with Bloom's taxonomy of educational objectives can also shed light on improvement opportunities. An independent evaluation of the influence of the course 
on students' experiences in industry, after graduation, beyond the anecdotal testimonial we have included above can lead to useful insights.

We are also creating executive in-house training programs based on the same pedagogy. Early experience with these is encouraging.

\section{References}

[1] Barnes, R. J., "Conflict and Ambiguity in Information Systems Development". Dissertation, Binghamton University, Binghamton, NY, July 2005.

[2] Barnes, R.J., Gause, D.C. and Way, E.C., "Teaching the Unknown and the Unknowable in Requirements Engineering Education", Proc. 3rd International Workshop on Requirements Engineering Education and Training (REET 2008), Barcelona, Spain, September 92008.

[3] Beatty, J. and Alexander, M., "Games-Based Requirements Engineering Training: An Initial Experience Report", Proc. 16th IEEE International Requirements Engineering Conference, Barcelona, Spain, 2008.

[4] Berenbach, B., "A Hole in the Curriculum", Proc. 1st International Workshop on Requirements Engineering Education and Training (REET 2005), Sorbonne, Paris, France, August 30, 2005.

[5] Beyer H. and Holtzblatt K., Contextual Design: A Customer-Centered Approach to System Designs, Morgan Kaufmann, 1997.

[6] Buchwalder, O. and Petitpierre, C., " Weblang: A language for modeling and implementing web applications", Proc. of the Eighteenth International Conference on Software Engineering and Knowledge Engineering (SEKE'06), San Francisco Bay, USA, July 5-7, 2006, pages 584-590.

[7] Checkland, P.and Holwell, S., Information, Systems and Information Systems - making sense of the field. Wiley, Chichester, UK, 1998.

[8] Cook, J. "An Interview with Barry Boehm" ICE2000 Windows on the World ezine Issue2, 2000.

http://www.ul.ie/\%7Eicse2000/wow/issue2/barry_boehm_int erview.htm. Accessed May 21, 2005.

[9] Cybulski, J., Parker, C. and Segrave, S. (2006): "Using constructivist experiential simulations in RE education", in Didar Zowghi \& Lemai Nguyen (eds), Proc. of the 11th Australian Workshop on Requirements Engineering, pp. 110, University of South Australia, South Australia.

[10] Damian, D., Al-Ani, B., Cubranic, D. and Robles, L., "Teaching Requirements Engineering in Global Software Development: A report on a three-University collaboration", Proc. 1st International Workshop on Requirements Engineering Education and Training (REET 2005), Sorbonne, Paris, France, August 30, 2005.

[11] Delaney, J.D, and Mitchell, G.G., "PBL applied to Software Engineering Group Projects", Proc. International Conference on Information and Communication Technologies in Education (ICTE 2002). Badajoz, Spain. Nov 13-16 2002.
[12] Gause, D.C. and Weinberg, G.M., Exploring Requirements: Quality BEFORE Design, Dorste House, New York, 1989

[13] Gause D.C., "Making the case for the soft in Software Engineering: What does it really take to be prepared for the RE world ahead?" Keynote address, (Abstract) Requirements Engineering Workshop on Education and Training (REET 2005), Sorbonne, Paris, France, August 30, 2005.

[14] Ghezzi, C. and Mandrioli, d., "The Challenges of Software Engineering Education", Proc. $27^{\text {th }}$ International Conference on Software Engineering (ICSE 2005), St. Louis, Missouri, May 15-21, 2005.

[15] IEEE Std 830-1998, IEEE Recommended Practice for Software Requirements Specifications, IEEE Computer Society, 1998.

[16] Intalio (2007). http://www.intalio.com, accessed February 2009.

[17] John-Steiner, V., "Cognitive Pluralism: A Sociocultural Appproach", Mind, Culture and Activity. Volume 2, No. 1, Winter 1995 1074-9039/95/2-11

[18] Kolb, D.A., Experiential Learning: Experience as the Source of Learning and Development, Prentice Hall, Englewood Cliffs, N.J. 1984.

[19] Madhavji, N.H. and Miller, J., "Investigation-based Requirements Engineering Education", Proc. 1st International Workshop on Requirements Engineering Education and Training (REET 2005), Sorbonne, Paris, France, August 30, 2005

[20] Mitchell, G.G. and Delaney, J.D., "An Assessment Strategy to Determine Learning Outcomes in a Software Engineering Problem-based Learning Course", Int. Journal of Engineering Education v. 20, n. 3, pp. 494-502, 2004.

[21] MIT Forum for Supply Chain Innovation (2007). http://beergame.mit.edu/, accessed March 2007.

[22] Nygard, K., "Participation in Sysems Development. The Task Ahead", Systems Design For, With, and By Users, Briefs, U., Ciborra, C. and L. Schneider (eds.), North Holland, 1983.

[23] Regev, G. and Wegmann, A., "Defining early IT system requirements with regulation principles: the lightswitch approach" in Proceedings 12th IEEE International Requirements Engineering Conference, Sorbonne, Paris, Sept. 6-10, 2004.

[24] Smith, R. and Gotel, O. "Gameplay to Introduce and Reinforce Requirements Engineering Practices", Proc. 16th IEEE International Requirements Engineering Conference, Barcelona, Spain, 2008.

[25] Sheppard, S.D., Macatangay, K., Colby, A., and Sullivan, W.M., Educating Engineers: Design for the Future of the Field Carnegie/Jossey-Bass, 2008.

[26] Shum, S. J. Buckingham, MacLean, A., Bellotti, V.M. E., Hammond, N.V., "Graphical Argumentation and Design Cognition”, Human-Computer Interaction, v.12 n.3, 1997.

[27] Vagliardo, M.W., "An Exploration of the Development of Cognitive Pluralism in a Purposefully Designed University Classroom", Ed.D. Dissertation, Binghamton University, Binghamton, NY, August 2000.

[28] Wegmann, A. "Theory and practice behind the course designing enterprise-wide IT systems", IEEE Transactions on Education, 47 (4), 2004, 490 - 496. 
[29] Wegmann, A., Regev, G., Rychkova, I., Lê, L-S, De La Cruz, J.D. and Julia, P., "Business-IT Alignment with SEAM for Enterprise Architecture", in Proc. 11th IEEE International EDOC Conference (EDOC 2007), Annapolis, Maryland, October 2007.

[30] Wegmann, A., Regev G., De la Cruz, J.D., Lê L-S and Rychkova I., "Teaching Enterprise and Service-Oriented Architecture in Practice", Enterprise Architecture 10:4, 2007. [31] Wegmann, A., Lê, L. S., Regev, G., and Wood, B., "Enterprise Modeling Using the Foundation Concepts of the RM- ODP ISO/ITU Standard," Information Systems and eBusiness Management (ISeB) v. 5, n. 4, 2007, p. 397-413.

[32] Weinberg, G. M. and Weinberg, D., General Principles of Systems Design. Dorset House. New York, 1988.

[33] Weinberg, G. M., Secrets of Consulting: A Guide to Giving and Getting Advice Successfully, Dorset House, New York, 1985.

[34] Zowghi, D. and Paryani, S., "Teaching requirements engineering through role playing: lessons learnt" in Proceedings 11th IEEE International Requirements Engineering Conference, Monterey Bay, CA, Sept. 8-11, 2003. 


\section{Appendix: Course Evaluation}

The short questionnaire is shown in Figure 5. The scores on question 1 were, $10,8,7,5,8,10$ and 4 . The last score was given by a student who admitted to not participating actively enough in the course because he was working during class hours.

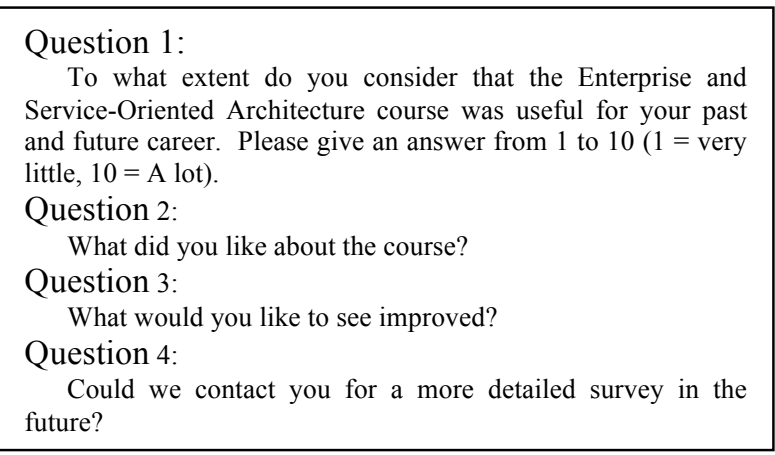

Figure 5: Graduate questionnaire

Following are the seven answers we received to questions 2 and 3:

\section{Question 2: What did you like about the course?}

- the practice side

- It made us think about the "project" in a whole and not only in an engineering point of view. the question on what would the business angel like to hear, etc. I would say maybe practice in general. And the content itself obviously!

- The different workshops when the professor and assistants play the role of somebody and we have to ask them questions

- $\quad$ The class was different that typical EPFL classes and we learned many very interesting things and we were able to see how they work in practice. This was a great combination.

- The training to obtain information about people working in the entreprise (role game). See a complete modelling process. People coming from other universities / entreprises $=>$ Application to reality.

- You've made the course really interesting. I really liked the professor's discussions about the [..] supply chain. Professional experiences are always interesting ${ }^{2}$.

\footnotetext{
${ }^{2}$ Original version in French: Vous avez rendu le cours intéressant. J'ai beaucoup aimé les interventions d'A.
}

- It was very interactive. Professor and TAs did a great job in creating scenarios that are most similar to the ones we could expect in reality. That gave us the opportunity to act under many constraints (making decisions under pressure, dealing with disagreements in the team, time deadlines, etc.). It was useful because later we discussed about our actions and made conclusions together about what we did good and what could have been done better and how.

\section{Question 3: What would you like to see improved?}

- improve documentation, more precise

- When the class will be more organised I believe it will be possible to deepen the aspects. If my memory is good, I found sometimes lack of fluency between some aspects/chapters.

- The explanations about the board. We first didn't understand why it was useful and begin to use it really at the end of the game

- Sometimes I felt lost - our group did not know what exactly we were supposed to do and how to deliver the results. We were doing things for the first time so we had plenty of questions and we felt that there were not enough assistants, even though they were working all their time. A good way to organizing it would be creation of secure group website (for example use my.epfl.ch) where assistants would post the tasks to do, some description for those who have questions and templates of documents to organize the work (or link to a page with all this for each class). This would also facilitate working within a group: once we are obliged to put the documents there, the entire group can access them later for a reference, revisions for the exams etc. This is just an idea of improvement. In general, the class is very good and we learned a lot - this is a way to make it easier to follow for further students.

- $\quad$ Slides were not very explicit, I've been ill a day and couldn't come and it was very

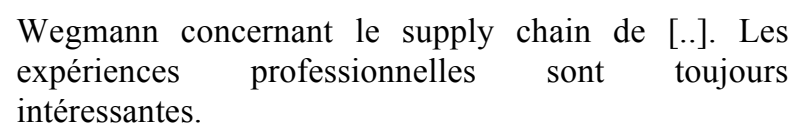
intéressantes. 
difficult to get the course through the slides.

- Rather than base the course on a simulated ERP why not use a real ERP? Why not present SAP? This is part of the common knowledge [in IT]. Many of us will be exposed one day to an ERP ${ }^{3}$.

- No particular suggestions.

${ }^{3}$ Original version in French: Plutôt que de baser le cours sur une simulation d'erp faite en weblang, pourquoi ne pas utiliser un vrai erp [..]. Pourquoi ne pas présenter SAP? Celà fait partie de la culture générale : beaucoup d'entre-nous seront une fois ou l'autre confrontés à un ERP. 